\title{
ANALYSIS OF POST LAUNCH ASSESSMENT OF PNEUMOCOCCAL CONJUGATED VACCINE DEMONSTRATION PROGRAM IN WEST LOMBOK AND EAST LOMBOK, WEST NUSA TENGGARA, 2018
}

\author{
Devi Anisiska, Adik Wibowo \\ Faculty of Public Health, Universitas Indonesia
}

\begin{abstract}
Background: Pneumonia is the major cause of mortality of under five children in the world, also in Indonesia. Considering high burden of the disease and good performance of immunization program in Lombok island, Ministry of Health introduced Pneumococcal Conjugated Vaccine (PCV) immunization in West and East Lombok districts since October 2017. This study aimed to evaluate and assess the implementation of PCV demonstration program in West Lombok and East Lombok. The aim of this article is to analyze the results of Post Launch Assessment of PCV demonstration program in East Lombok and West Lombok districts, West Nusa Tenggara province.

Subjects and Methods: Post Launch Assessment (PLA) was conducted using PLA tools which was developed together between Ministry of Health and CHAI. It was adapted from the instruments of Supportive Supervision, Post Introduction Evaluation WHO dan Effective Vaccine Management UNICEF. The assessment was carried out in all community health centre (Puskesmas) which implementing PCV demostration program, 32 Puskesmas at East Lombok Districts and 19 Puskesmas at West Lombok Districts. The datas were collected through interview to immunization officer, Head of Puskesmas and vaccinators and through observed immunization services at Posyandus, facilities and infrastructure at Puskesmas also register and logistic books. Ministry of Health assisted by Clinton Health Access Initiative (CHAI) conducted this activities in May - September 2018.

Results: Several components of assessment that need special attention were: (1) Cold chain, (2) Recording and reporting system, (3) Management of vaccine and logistics, (4) Monitoring and analysis of the program, and (5) Adverse Event Following Immunization (AEFI) surveillance.

Conclusion: PCV demonstration program in West Lombok and East Lombok are well implemented. But for better implementation in the future, the recommendations are: (1) Supplementary vaccine distribution system to cover limited vaccine storage capacity or alternative provision of vaccines with smaller volumes preparation, (2)Printing Immunization Recording and Reporting Books with additional columns for PCV especially for districts who conduct PCV demonstration program, (3) Strengthening management of vaccine and logistics, especially for vaccine requirements calculation, vaccine stock recording and temperature monitoring, and (4) Strengthening data analysis capability of immunization officer at Puskesmas level to do immediate follow up of the problem.
\end{abstract}

Keywords: pneumonia, Pneumococcal Conjugated Vaccine, immunization, demonstration program, post launch assessment

\section{Correspondence:}

Puri Primacom. Residence Blok F-5 Cinangka Sawangan, Depok, West Java, Indonesia. Email: anisiskadevi@gmail.com. Mobile: 081808303579. 